Advances in measuring ocean salinity with an optical sensor

This article has been downloaded from IOPscience. Please scroll down to see the full text article.

2011 Meas. Sci. Technol. 22115202

(http://iopscience.iop.org/0957-0233/22/11/115202)

View the table of contents for this issue, or go to the journal homepage for more

Download details:

IP Address: 129.20.223.20

The article was downloaded on 29/09/2011 at 08:45

Please note that terms and conditions apply. 


\title{
Advances in measuring ocean salinity with an optical sensor
}

\author{
M Le Menn ${ }^{1}$, J L de Bougrenet de la Tocnaye ${ }^{2}$, P Grosso $^{2}$, L Delauney ${ }^{3}$, \\ C Podeur ${ }^{3}$, P Brault $^{4}$ and O Guillerme ${ }^{4}$ \\ ${ }^{1}$ Service Hydrographique et Océanographique de la Marine (SHOM), 13 rue du Chatellier, CS 92803, \\ 29228 Brest Cédex 2, France \\ 2 TELECOM Bretagne, Technopôle de Brest-Iroise, CS 83818, 29238 Brest Cédex 3, France \\ ${ }^{3}$ IFREMER, 155 rue Jean-Jacques Rousseau, 92138 Issy les Moulineaux Cédex, France \\ ${ }^{4}$ NKE, Z.I. de Kerandré, 56700 Hennebont, France \\ E-mail: marc.lemenn@shom.fr
}

Received 7 February 2011, in final form 3 August 2011

Published 13 September 2011

Online at stacks.iop.org/MST/22/115202

\begin{abstract}
Absolute salinity measurement of seawater has become a key issue in thermodynamic models of the oceans. One of the most direct ways is to measure the seawater refractive index which is related to density and can therefore be related to the absolute salinity. Recent advances in high resolution position sensitive devices enable us to take advantage of small beam deviation measurements using refractometers. This paper assesses the advantages of such technology with respect to the current state-of-the-art technology. In particular, we present the resolution dependence on refractive index variations and derive the limits of such a solution for designing seawater sensors well suited for coastal and deep-sea applications. Particular attention has been paid to investigate the impact of environmental parameters, such as temperature and pressure, on an optical sensor, and ways to mitigate or compensate them have been suggested here. The sensor has been successfully tested in a pressure tank and in open oceans $2000 \mathrm{~m}$ deep.
\end{abstract}

Keywords: refractive index, seawater, density, salinity, refractometer

(Some figures in this article are in colour only in the electronic version)

Glossary
$A$
$A_{i}$ and $B_{i}$
$\alpha_{G}, \alpha_{S i}$
$C_{1}, C_{2}, C_{3}$
$\mathrm{~d} \lambda / \mathrm{d} t$
$\mathrm{~d} n$
$\mathrm{~d} n_{\text {glass }} / \mathrm{d} p$
$\mathrm{~d} n_{\mathrm{Glass}} / \mathrm{d} t$
$\delta P(t, \lambda, p)$
$\mathrm{d} P$
$\mathrm{~d} r$
$\delta S_{\mathrm{A}}$ dens
$\varepsilon$
$\xi$

incident angle $\left(^{\circ}\right)$

coefficients of the Sellmeier relation expansion coefficients of glass and silicon $\left(\mathrm{m}^{-1}\right)$ constants

laser wavelength sensitivity to temperature $\left(\mathrm{nm} /{ }^{\circ} \mathrm{C}\right)$

fluid refractive index variation pressure-optical coefficient (/dbar) thermo-optical coefficient of glasses $\left(/{ }^{\circ} \mathrm{C}\right)$ correction to apply to the position $P(\mu \mathrm{m})$ variation of the laser beam position $(\mu \mathrm{m})$ corresponding to $\mathrm{d} n_{\text {sea }}$ variation of the refractive angle $r\left(^{\circ}\right)$ absolute salinity-density variation dielectric constant proportionality constant
Gibbs function refractive angle $\left({ }^{\circ}\right)$ constant wavelength $(\mathrm{nm})$ length of the beam path $(\mu \mathrm{m})$ theoretical maximal length of the beam path $(\mu \mathrm{m})$ number of molecules per unit volume fluid refractive index refractive index of the left prism refractive index of the right prism molecular mean polarizability molar refractivity spot position on the PSD $(\mu \mathrm{m})$ pressure (dbar) refractive angle $\left(^{\circ}\right)$ density $\left(\mathrm{kg} \mathrm{m}^{-3}\right)$ standard deviation 


$\begin{array}{ll}S_{A} & \begin{array}{l}\text { absolute salinity }\left(\mathrm{g} \mathrm{kg}^{-1}\right) \\ \text { absolute salinity calculated from density } \\ S_{A} \text { dens }\end{array} \\ S_{p} & \begin{array}{l}\text { measurements } \\ \text { practical salinity (no unit) }\end{array} \\ S_{R} & \begin{array}{l}\text { reference salinity }\left(\mathrm{g} \mathrm{kg}^{-1}\right) \\ \theta\end{array} \\ T & \begin{array}{l}\text { half-angle between two prisms }\left(^{\circ}\right) \\ \text { absolute temperature }(\mathrm{K})\end{array} \\ t & \text { temperature }\left({ }^{\circ} \mathrm{C}\right) \\ W & \text { molecular weight }\end{array}$

\section{Introduction}

The most recent definition of the thermodynamic equations of seawater [1] (TEOS-10) given by the UNESCO/IOC SCOR/IAPSO working group 127 (WG127), based on a Gibbs potential function of absolute salinity $S_{A}$, temperature $T$ and pressure $p$, focuses on the absolute salinity assessment. Nowadays, seawater salinity is calculated by formulas of the practical salinity scale of 1978 (PSS-78) [2, 3] based on conductivity ratio measured by conductance sensors. But, for seawater samples with a different composition from standard seawater, practical salinity values $S_{p}$ (which are dimensionless) present some biases [4].

First, they do not take into account non-ionic compounds dissolved in seawater causing deviations between $S_{A}$ and $S_{p}, S_{A}$ being the mass fraction of the dissolved material in a given seawater sample, measured in standard conditions. $S_{A}$ (expressed in $\mathrm{g} \mathrm{kg}^{-1}$ ) is directly related to density $\rho$, a fundamental quantity in oceanography, and in order to take into account the problems related to the traceability to the international system of units (SI), the WG127 has defined the notion of 'density salinity' $S_{A}$ dens, which is the mass fraction of solution which has the same density as the sample it comes from in standard temperature and pressure conditions. Models were built to correct differences between $S_{A}$ and $S_{p}$, and in 2009 McDougall et al [4] proposed to use the relation $S_{A}=$ $S_{R}+\xi \delta S_{A}{ }^{\text {dens }}$, where $S_{R}$ is a reference salinity calculated from practical salinity measurement, $\xi$ a proportionality constant and $\delta S_{A}{ }^{\text {dens }}$ an empirical value obtained from a salinity value calculated from direct density measurements using the relation $\rho=1 / g_{P}\left(S_{R}, t, p\right)$, where $g_{P}$ is the Gibbs function [5]. McDougall et al [4] assessed the value of $\delta S_{A}{ }^{\text {dens }}$ and found it to be as large as $0.025 \mathrm{~g} \mathrm{~kg}^{-1}$ 'in the northernmost North Pacific' open ocean, mostly because of silicates which are non-ionic compounds. The assessment of this value is more delicate in coastal and estuarine waters.

Second, as shown by Setz et al [6], the so-called IAPSO/standard seawater is used to calibrate laboratory salinometers so that conductance sensors, and more precisely the reference salinity value, can be determined with a standard uncertainty of 0.01 with respect to the SI conductance standards, whereas the oceanographers' community expects uncertainty values close to 0.002 . According to Setz, it means that long timescale traceability of salinity measurements can be done only with a relative standard uncertainty of $3 \times 10^{-4}$, which is too large for oceanographic purposes. Furthermore, the uncertainty of $\xi \delta S_{A}$ dens is difficult to estimate with respect to the SI, leading to SI-incompatible estimates of $S_{A}$ [7].
Finally, conductivity depends strongly on temperature. That leads to difficulties in aligning response times of conductance and temperature sensors. Because of $S_{p}$ calculation with the PSS-78 relations, misalignments lead to artifacts in salinity values, especially when measurements are made in non-mixed thermoclines. Even when data are corrected by the correction algorithms of the instruments provided by the manufacturers, errors as large as 0.017 (on average) persist for measurements in strong salinity gradients [8]. This increases the expected uncertainty in practical salinity values.

To avoid these biases, accurate measurements of the seawater refraction index have become an area of particular interest. In 2009, we developed a method using advances in high resolution position sensitive devices (PSD), taking advantage of small beam deviation measurements by a twinprism refractometer (TRP) [9]. This method has been employed to build a prototype, usable in open ocean to a depth of $2500 \mathrm{~m}$. In its development, special attention has been paid to the impact of environmental parameters, such as temperature and pressure on the optical sensor or temperature wavelength drift of the laser, and the ways in which these have been mitigated or compensated. Salinity calculation and environmental variables compensation have been possible only by integrating into the instrument sensors to measure external temperature and pressure and the laser's internal temperature. This prototype has been tested successfully, in a pressure tank and at sea to a depth of $2000 \mathrm{~m}$ during an oceanographic cruise, and we have obtained the first deep-sea index profile, calibrated in salinity.

\section{Refractive index and density measurements theoretical background}

It is well known that density and absolute salinity can be assessed by a direct measurement of the refractive index. Different relations have been established to express the refractive properties of fluids as a function of their state parameters [10]: $n^{2}-1=K \rho$ found by Newton and Laplace (1821), $n-1=K \rho$ found by Gladstone and Dale (1863), $\left(n^{2}-1\right) /(n+0.4)=K \rho$ found by Eykman (1895) and

$$
\frac{n^{2}-1}{n^{2}+2}=K \rho
$$

found independently by Lorentz and Lorenz, in the same year (1880), where $K$ is a constant. The Lorentz-Lorenz formula is the only one justified theoretically [11], and its second member is generally expressed in terms of molecular mean polarizability $m_{p}$ and number of molecules per unit volume $N$. Relation (1) can then be written as

$$
m_{p}=\frac{3}{4 \pi N} \frac{(\varepsilon-1)}{(\varepsilon+2)},
$$

$\varepsilon$ being the dielectric constant. If the molecular weight $W$ of the species present in the fluid is known (as is the case for reference seawater [12]), the Lorentz-Lorenz relation can be expressed in terms of molar refractivity $m_{r}$, and relations (1) and (2) give

$$
\frac{n^{2}-1}{n^{2}+2}=\frac{m_{r} \rho}{W} .
$$


For pure water, according to Reisler and Eisenberg, this equation does not describe correctly the observed shift between the temperature of the maximal refractive index and the temperature of the maximal density. They proposed in 1965 a semi-empirical relation describing the variation of the water refraction index [13]:

$$
\frac{n^{2}-1}{n^{2}+2}=C_{1} \rho^{C_{2}} \mathrm{e}^{-C_{3} t} .
$$

In relation (4), $C_{1}, C_{2}$ and $C_{3}$ are constants depending on the wavelength $\lambda$. In 1984, Saubade showed that even in the case of water, the Gladstone-Dale refringence formula combined with the Reisler-Eisenberg relation gives the best results and can be generalized to any kind of liquid [14]. But, in the earlier formulation, Thormählen et al verified the assumption that, if the Lorentz-Lorenz relation depends strongly on the wavelength, it varies slowly with temperature (no more than $1 \%$ between ambient temperature and boiling point) and molar density [15]. Hence, the molar refractivity of pure water behaves in the same way as any other elementary fluid, for a given wavelength. This can be theoretically explained and modeled by an empirical relation function of $\rho, t$ and $\lambda$ [16].

Contrarily, several authors attempted to establish empirical relations between the seawater refractive index and its variations in temperature, salinity and pressure. In 1990, Millard and Seaver proposed a 27 term algorithm covering the range $500-700 \mathrm{~nm}$ in wavelength, $0-30{ }^{\circ} \mathrm{C}$ in temperature, $0-40$ in practical salinity and $0-11000$ dbar in pressure to compute the seawater refractive index [17]. By measuring the refractive index and inverting this algorithm, salinity can be extracted with accuracies close to oceanographic purposes at low pressure, but not at high pressure. This algorithm establishes a link between practical salinity and refractive index but, more recently, Millero and Huang have published relations between $S_{A}$ and $\rho$, usable in the ranges of salinity 5-70 $\mathrm{g} \mathrm{kg}^{-1}$ and temperature 273.15-363.15 K, with a standard error of $0.0036 \mathrm{~kg} \mathrm{~m}^{-3}$ in density, compatible with oceanographic purposes. Such relations are not usable with pressure values, but at this time, density can be computed as a function of practical salinity and pressure using Millero et al's equation [18]. This equation has been recently improved by measurements on standard seawater corresponding to $S_{A}=35.16504 \mathrm{~g} \mathrm{~kg}^{-1}$, and extended temperature and pressure ranges [19], making density a good candidate for salinity traceability to SI [7], and refractometry for indepth measurements, well suited to expected oceanographic accuracy.

\section{Theoretical principle of the refractometer}

Optical technologies for a long time have been considered irrelevant in performing salinity measurements in depth and in open oceans, due to the ocean medium constraints [20]. Reported developments of sensor prototypes never resulted in regular applications due to lack of stability or reliability under temperature and pressure. Recent advances in high resolution PSD measuring beam deviations have enabled (with a $12 \mathrm{~mm}$ Hamamatsu S3932) a full exploitation of

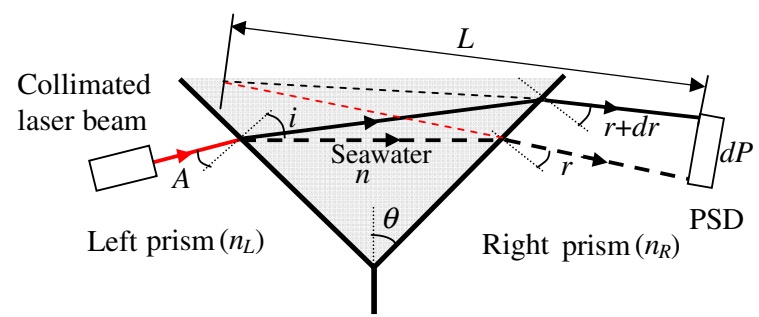

Figure 1. Schematic diagram of TPR.

fine deviations achievable by refractometers according to WG 127 requirements (i.e. uncertainty on refractive index of 1 ppm at atmospheric pressure and $3 \mathrm{ppm}$ at high pressure). Various optical implementations are possible but for salinity measurements, where the impact of environmental features is critical, a TPR [9] has been preferred for providing an intrinsic index thermal compensation (see figure 1).

TPR beam deviations are directly derived from the following Snell-Descartes refraction laws:

$n_{L} \sin (A)=n \sin (i) \quad$ and $\quad \sin (r)=\frac{n}{n_{R}} \sin (2 \theta-i)$

with $n_{L}$ and $n_{R}$ being the refractive indices of the left and right prisms. Hence, the beam deviation $\mathrm{d} r$ can be easily expressed as a function of the sea index variation $\mathrm{d} n$ :

$$
\begin{aligned}
\frac{\cos (r)}{\sin (r)} \mathrm{d} r & =\frac{\sqrt{1-\frac{n}{n_{R}} \sin (2 \theta-i)^{2}}}{\frac{n}{n_{R}} \sin (2 \theta-i)^{2}} \mathrm{~d} r \\
& =\left(1+\frac{\cos (2 \theta-i) \sin (i)}{\sin (2 \theta-i) \cos (i)}\right) \frac{\mathrm{d} n}{n} \\
\frac{\mathrm{d} n}{\mathrm{~d} r} & =\frac{n_{R} \cos (i)}{\sin (2 \theta)} \sqrt{1-\left(\frac{n}{n_{R}} \sin (2 \theta-i)\right)^{2}}
\end{aligned}
$$

with

$$
\cos (i)=\sqrt{1-\left(\frac{n_{L}}{n} \sin (A)\right)^{2}} \text { and } \mathrm{d} r=\tan ^{-1}\left(\frac{\mathrm{d} P}{L}\right) .
$$

From (7) and (8), the refractive index resolution $\mathrm{d} n$ is obtained as

$$
\begin{aligned}
\mathrm{d} n= & \frac{n_{R}}{\sin (2 \theta)} \sqrt{1-\left(\frac{n_{L}}{n} \sin (A)\right)^{2}} \\
& \times \sqrt{1-\left(\frac{n}{n_{R}} \sin (2 \theta-i)\right)^{2}} \tan ^{-1}\left(\frac{\mathrm{d} P}{L}\right) .
\end{aligned}
$$

Relation (9) exhibits the design parameters $\left(L, A, \theta, n_{L}, n_{R}\right)$, to which the laser wavelength $\lambda$ should be added. Most of these parameters depend on environmental parameters $(t, p)$. Theoretically, $L$ can be adjusted according to the required resolution where the main parameter impacting the refractive index resolution is the incidence angle $A$. Figure 2 shows this dependence for $\theta=\pi / 4, \mathrm{~d} P / L=1.7 \mu \operatorname{rad}(\mathrm{d} P=0.1 \mu \mathrm{m}$, $L=60 \mathrm{~mm}$ ) and $n=1.34$.

A good trade-off is to choose $A$ between the minimum deviation $\left(\sim 40^{\circ}\right)$ and total reflection $\left(\sim 60^{\circ}\right)$. The minimum 


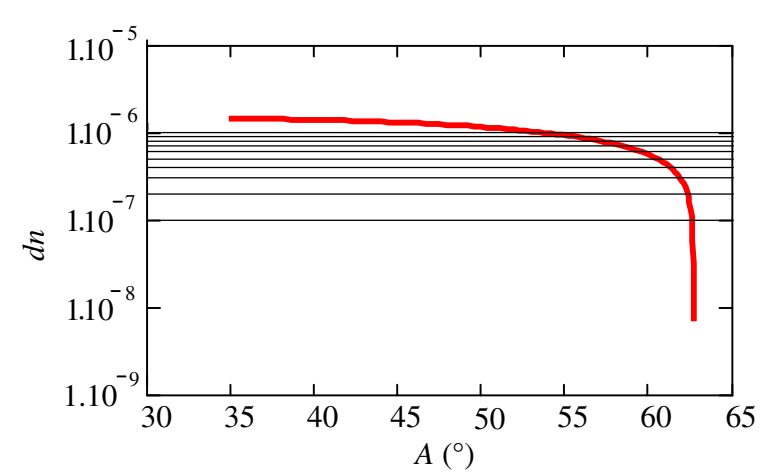

Figure 2. Sensitivity of seawater refractive index to incident angle $A$.

deviation requires long prisms to cover the PSD, whereas near total reflection is impinged by beam vignetting as well as the presence of turbid zone, at the two prisms junction. Figure 2 illustrates that with $A=50^{\circ}, \mathrm{d} n$ is greater than $1 \mathrm{ppm}$. Even if it seems that length $L$ can be freely adjusted, it is practically not the case. It is better to reduce the thermal inertia of the optical block by limiting the glass volume.

Two main environmental parameters that will impact the performance are pressure and temperature. The pressure impacts the glass refractive index with a coefficient $\mathrm{d} n_{\text {Glass }} / \mathrm{d} p=4 \times 10^{-8} / \mathrm{dbar}$ [21]. If the pressure is known with an accuracy of $2 \mathrm{dbar}$, the added uncertainty on salinity is $\ll 10^{-3} \mathrm{~g} \mathrm{~kg}^{-1}$, and can be neglected. However, it is not the case for the temperature which impacts several parameters such as the laser wavelength $\mathrm{d} \lambda / \mathrm{d} t$, the refractive indices of glasses $\mathrm{d} n_{L} / \mathrm{d} t$ and $\mathrm{d}\left(\mathrm{d} n_{R}\right) / \mathrm{d} t$, the optical path length $\mathrm{d} L / \mathrm{d} t$ and the PSD length $L \mathrm{~d} r / \mathrm{d} t$. Before estimating the influence of temperature on wavelength and refractive indices, let us determine the maximum length $\left(L_{\max }\right)$, beyond which it is impossible to maintain the refractometer resolution without electronic correction.

Figure 3 shows the optical block and sensor expansions as a function of $L$. Due to symmetry along the PSD axis, the calculation is performed on one-half of the PSD and for positive value $t-t_{0}$. Using $\alpha_{G}$ and $\alpha_{\mathrm{Si}}$, the expansion coefficients of glass (optics) and silicon (PSD), respectively, we obtain

$\mathrm{d} P_{G}=\mathrm{d} r_{\max } \times \alpha_{G} \times L \times\left(t-t_{0}\right) \quad$ and

$\mathrm{d} P_{\mathrm{Si}}=\mathrm{d} r_{\max } \times \alpha_{\mathrm{Si}} \times L \times\left(t-t_{0}\right)$

then: $\quad \mathrm{d} P=\left(\alpha_{G}-\alpha_{\mathrm{Si}}\right) \times \mathrm{d} r_{\max } \times L \times\left(t-t_{0}\right)$.

Consequently, the laser beam positioning error on the PSD as a function of the length $L$, for a deflection angle $\mathrm{d} r_{\max }$ corresponding to a refractive index variation of $0.01(A=$ $\left.55^{\circ}\right)$, a temperature change $t-t_{0}=20{ }^{\circ} \mathrm{C}, \alpha_{G}=12.7 \times$ $10^{-6}, \alpha_{\mathrm{Si}}=2.6 \times 10^{-6}$ follows a linear variation. Therefore, maintaining a positioning accuracy close to the PSD resolution without off-line corrections results in an optimum length $\left(L_{\max }\right)$. This enables us to deduce from (5) the refraction angle $\mathrm{d} r$ corresponding to a seawater refractive index change of \pm 0.01 (compared to 1.34) and determine the most suitable

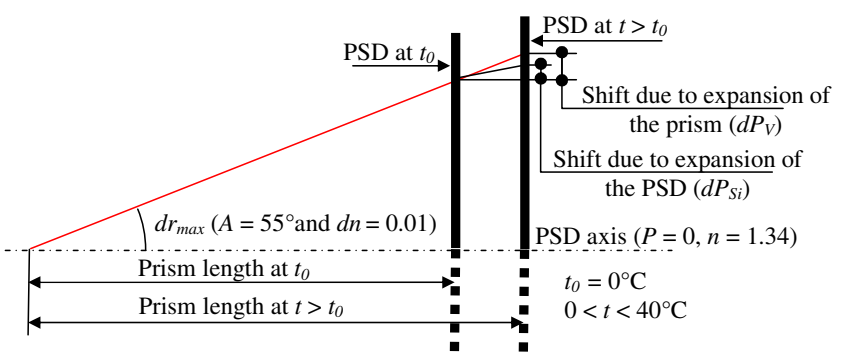

Figure 3. Positioning error due to prism and PSD expansion.

PSD. For instance, with a PSD resolution of $0.2 \mu \mathrm{m}$ we obtain a length $L \approx 60 \mathrm{~mm}$, with $\mathrm{d} n= \pm 0.01, \theta=\pi / 4, A=$ $55^{\circ}, n=1.34, n_{L}=1.515090$ and $n_{R}=1.486010$, and $\mathrm{d} r$ which is equal to $\pm 19 \mathrm{mrad}$. To guarantee this resolution, the laser beam should cover the usable PSD part (with the smallest beam waist) according to the considered refractive index (or salinity) range. Three types of high-resolution PSD are available: $3 \mathrm{~mm}(0.1 \mu \mathrm{m}), 6 \mathrm{~mm}(0.2 \mu \mathrm{m}), 12 \mathrm{~mm}$ $(0.3 \mu \mathrm{m})$. By subtracting the laser beam waist $(\sim 500 \mu \mathrm{m})$, we obtain $L_{3 \mathrm{~mm}}=65.8 \mathrm{~mm}, L_{6 \mathrm{~mm}}=144.7 \mathrm{~mm}$ and $L_{12 \mathrm{~mm}}=302.6$ $\mathrm{mm}$. According to the above consideration, the expansion effect can only be neglected with the $3 \mathrm{~mm}$ PSD, maintaining the maximum refractometer resolution.

To make the optics insensitive to temperature variations, twin prisms (two half-prisms equivalent to Schott N-BK7 and N-FK5) are used whose thermo-optical coefficients have the same value but opposite signs. From $0^{\circ}$ to $40{ }^{\circ} \mathrm{C}$, $\left(\mathrm{d} n_{L} / \mathrm{d} t\right)=1.7 \times 10^{-6}{ }^{\circ} \mathrm{C}^{-1}$ and $\left(\mathrm{d} n_{R} / \mathrm{d} t\right)=-1.7 \times$ $10^{-6}{ }^{\circ} \mathrm{C}^{-1}$. The refractive index variation of both optical prisms results in a self-compensated variation of beam angular deflection. However, the latter causes a shift of the output beam on the PSD. This implies that this shift is compensated by the same shift of the PSD. A solution to make the sensor fully insensitive to the thermo-optical effect is a PSD set-up on a substrate, to which the differential expansion coefficient allows a PSD motion of the same value. The laser beam shift due to $\mathrm{d} n_{\text {Glass }} / \mathrm{d} t$ equals minus the expansion holder shift $(x)$ due to $\mathrm{d}_{\text {lengthholder }} / \mathrm{d} t$. The last parameter to be considered is the laser wavelength dependence on temperature $\left(0.2 \mathrm{~nm} /{ }^{\circ} \mathrm{C}\right)$. Temperature changes will cause a wavelength drift itself causing a refractive index change. This drift can be compensated electronically using the Sellmeier relationship [22]

$$
n_{\text {Glass }}^{2}=1+\frac{A_{1} \lambda^{2}}{\lambda^{2}-B_{1}}+\frac{A_{2} \lambda^{2}}{\lambda^{2}-B_{2}}+\frac{A_{3} \lambda^{2}}{\lambda^{2}-B_{3}}
$$

where $A_{i}$ and $B_{i}$ are the coefficients provided by the respective manufacturers (e.g. Schott). These data allow the establishment of equations to compensate the refractive indices $n_{L}$ and $n_{R}$ with a good standard deviation $\left(\sigma=4 \times 10^{-8}\right)$ :

$n_{L}=3 \times 10^{-9} t^{2}-5.21 \times 10^{-6} t+1.5151172 \quad$ and

$n_{R}=2 \times 10^{-9} \mathrm{t}^{2}-7.666 \times 10^{-6} t+1.4860987$.

For a given temperature and given wavelength, computed refractive indices are introduced into (9) to obtain $\mathrm{d} n$. Another option consists in controlling the laser diode temperature. 


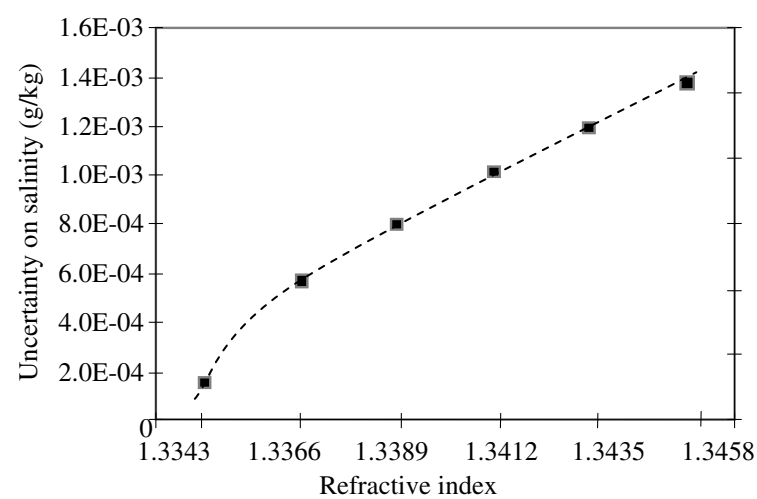

Figure 4. Assessment from a theoretical functioning model of the uncertainty linked to the variation of the refractive angle on salinity measurements as a function of the medium refractive index. The refractive angle decreases when salinity increases.

A self-compensation of $\mathrm{d} \lambda / \mathrm{d} t$ is however difficult and/or expensive. A solution reducing this dependence by a factor 10 $\left(0.02 \mathrm{~nm}{ }^{\circ} \mathrm{C}^{-1}\right)$ consists in using a broadband diode coupled with an interference filter. A salinity uncertainty of a few $10^{-3} \mathrm{~g} \mathrm{~kg}^{-1}$ can be obtained, over the full salinity range of $0-42 \mathrm{~g} \mathrm{~kg}^{-1}$, the refractive index varying from 1.3325 (distilled water at room temperature and atmospheric pressure) to 1.3458 (the most salted seawater at $0{ }^{\circ} \mathrm{C}$ and 250 bar). This uncertainty can be improved, close to $10^{-3} \mathrm{~g} \mathrm{~kg}^{-1}$, in the max deviation angle configuration. This value is even better for small salinity (figure 4). Values of $2.4 \times 10^{-4} \mathrm{~g} \mathrm{~kg}^{-1}$ have been obtained $\left(10 \mathrm{~g} \mathrm{~kg}^{-1}\right)$ [23] making it appropriate for deep-sea measurements. The choice of angle $A$ depends on the PSD available resolution and the considered salinity range resulting in dedicated configurations for deep-sea or coastal applications. Optical sensors provide direct access to the absolute salinity unlike conductivity sensors exhibiting intrinsic errors of about $0.16 \mathrm{~g} \mathrm{~kg}^{-1}$ on the absolute salinity in some oceanic areas. They require a temperature and pressure accuracy of $2.10^{-2}{ }^{\circ} \mathrm{C}$ and $1 \mathrm{dbar}$ to compute salinity (i.e. with an order of magnitude smaller than for conductivity sensors).

\section{Development and integration of the NOSS prototype}

The refractometer has been containerized in order to make it usable for in situ environmental media used in oceanography such as surface buoys, sea bottom observatories, profiling Provor floats, gliders and CTD (conductivity, temperature, depth) profilers. Compactness, pressure, temperature inertia and corrosion have been major concerns during the design. This prototype has been called NOSS for the NKE optical salinity sensor.

Unlike the prototype described in [9], the beam path has been deviated by gold mirrors deposited on angles of the prisms specially sized to reflect the beam on the PSD (figure 5(a)). In this way, the laser diode and the PSD are on the same side of the instrument, making integration in a container easier (figure 5(a)). A thermistor calibrated with Steinhart-Hart relation to an uncertainty of $\pm 0.005{ }^{\circ} \mathrm{C}$ has been used to measure the water temperature near the optical sensing area.
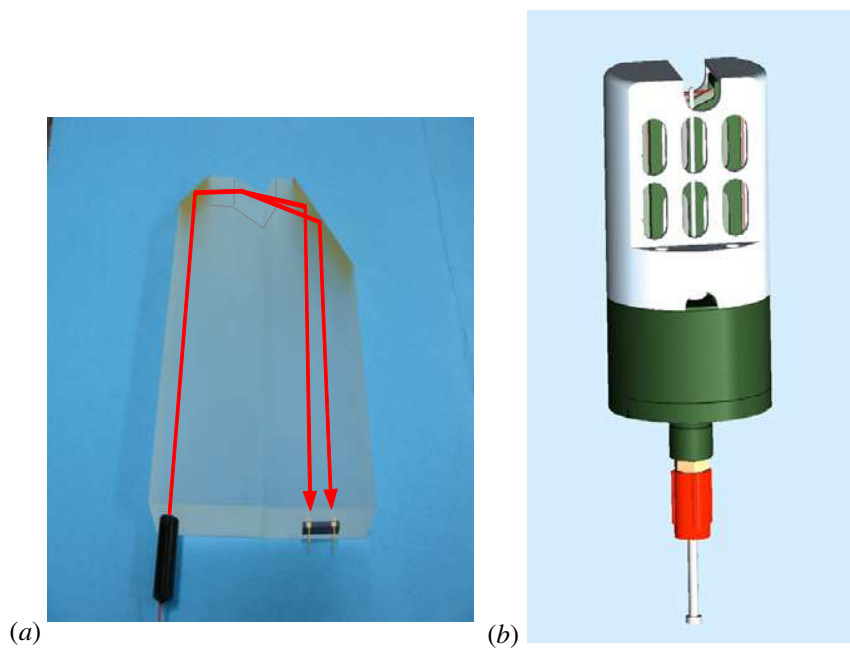

Figure 5. (a) Optical part with the laser on the left and the PSD on the right. The two beam paths correspond to the refractions obtained with seawater on the left and with distilled water on the right.

(b) NOSS sensor containerization. At the top part of the instrument, the measurement area is visible with the external temperature sensor contained in a long stainless steel rod. At the bottom part, there are the electronic container and the connector.

This thermistor is protected from pressure and humidity effects by using a stainless steel thin rod (figure 5). The laser temperature is measured by a second thermistor calibrated to an uncertainty of $\pm 0.01{ }^{\circ} \mathrm{C}$, fixed near it, inside the electronic container. A pressure sensor has been integrated near the base of the two prisms. Its measurement range is $0-300$ bar and its initial accuracy $\pm 0.05 \%$.

Specific mechanical design and materials have been used in order to optimize the optical cell mounting in order to obtain complete independence versus temperature variations and pressure. The NOSS container has been tested under pressure up to 350 bar to check its tightness. A specific electronic board has been designed to allow high frequency measurements up to $24 \mathrm{~Hz}$ in order to make it compatible with CTD profilers. Special care has been taken during electronic design in order to reduce as much as possible the power consumption and measurement noise. The electronic system measures laser position up to the PSD, laser temperature and in situ temperature and pressure, in order to compute final high precision density and salinity. The NOSS sensor is powered by a $12 \mathrm{~V}$ supply and consumes less than $600 \mathrm{~mW}$. It has been successfully tested in laboratory to evaluate adverse effects due to in situ fluorescence and turbidity.

\section{Calibration and correction in temperature, wavelength and pressure of the prototype}

In order to assess the characteristics of the index measurements, the sensor has been placed in a calibration bath filled with seawater $\left(S_{p}=34812\right.$, turbidity $\left.=0.7 \mathrm{NTU}\right)$ through which thermal stability can be regulated to 0.001 ${ }^{\circ} \mathrm{C}$ peak to peak, over $20 \mathrm{~min}$, between $0{ }^{\circ} \mathrm{C}$ and $35{ }^{\circ} \mathrm{C}$. The sensor's noise has been measured at $10{ }^{\circ} \mathrm{C}$, in the bath stirred and not stirred. Stirring is produced by a propeller which generates strong helicoid laminar ascendant movements 


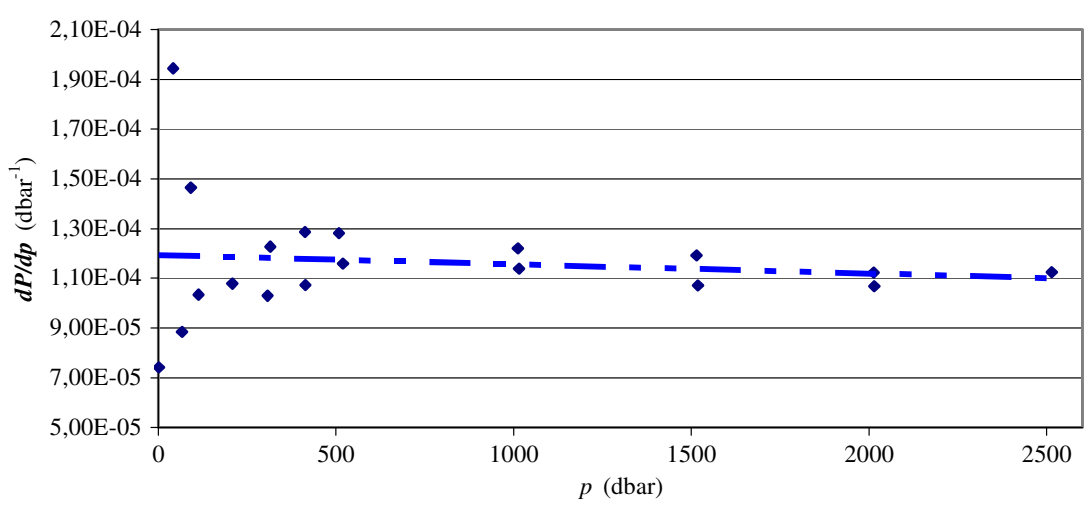

Figure 6. Dots represent the sensitivity of the PSD position $(P)$ as a function of pressure $(p)$ applied during the experiment in the pressure tank. The straight line is the average correction applied to the data. Under $500 \mathrm{dbar}$, the position data show an increasing discrepancy due to the inaccuracy of the corrections applied to the measured $P$. These corrections are necessary because the salinity decreased by 0.059 and the temperature by $1.508^{\circ} \mathrm{C}$ during the measurements. But, by applying an average sensitivity $\mathrm{d} P / \mathrm{d} n=81.431$ on the residual position errors, these discrepancies correspond only to maximal residual errors of $9 \times 10^{-7}$ for increasing pressures and $-5 \times 10^{-7}$ for decreasing pressures, on the index.

of water. It appears that the two extreme conditions of measurements generate average shifts in the order of only $1 \times 10^{-6}$ in the value of the index but the stirring generates standard deviations four or five times higher than the quiet water where the index standard deviation is also in the order or less than $1 \times 10^{-6}$. It is explained probably by the index micro-gradients generated by quick variations of temperature as the beam crosses the measurement volume.

Despite the careful design of the sensor, the laser spot position on the PSD is sensitive to the temperature of the PSD, the pressure applied on the prisms and the wavelength variations due to the laser temperature. So, it is necessary to apply corrections $\delta P$ on the measured positions $P$, as follows:

$$
\delta P(t, \lambda, p)=\frac{\partial P}{\partial n}\left[\frac{\partial n}{\partial t} \delta t+\frac{\partial n}{\partial \lambda} \delta \lambda+\frac{\partial n}{\partial p} \delta p\right],
$$

where $\partial n / \partial \lambda, \partial n / \partial t$ and $\partial n / \partial p$ are obtained by deriving, with respect to $\lambda, t$ or $p$, the four expressions of Millard and Seaver algorithm [17]. Laser diode sensitivity to temperature variations requires a correction of wavelength values used to compute the refractive index. The laser sensitivity to temperature has been measured: $\mathrm{d} \lambda / \mathrm{d} t=0.1899 \mathrm{~nm}{ }^{\circ} \mathrm{C}^{-1}$. However, $\partial n / \partial \lambda$ is not constant to the needed accuracy for salinity variations $>1$ unit, and it is necessary to estimate the salinity value before computing the correction $\delta P(\lambda)$. $\partial P / \partial n$ can be obtained by computing relation (9) and approximating $n$, or by measurements during the calibration. $\partial P / \partial n$ is then approximated per segment, by calculating position, index and temperature differences between temperature levels generated stepwise between $0{ }^{\circ} \mathrm{C}$ and $30{ }^{\circ} \mathrm{C}$, in order to determine $\partial P / \partial t$ as well. Salinity being constant to \pm 0.001 and pressure variations being negligible during the measurements, it appears that the sensitivity $\partial P / \partial t$ can be corrected by a simple second order polynomial of this kind: $\delta P(t)=0.110 \times$ $\left(-0.0040919-2.837 \times 10^{-4} t+1.3 \times 10^{-6} t^{2}\right)\left(r^{2}=0.9998\right)$.

Then, pressure effects on $P$ have been studied in a pressure tank. The sensor has been placed in a container equipped with a bladder sensitive to pressure and a CTD profiler (SBE 37, Sea Bird Electronics), in order to measure conductivity, temperature and pressure variations. The container has been filled with seawater $\left(S_{p}=33.8\right)$, placed in the pressure tank, and pressure levels have been applied from atmospheric pressure to 2500 dbar. It appeared that $P$ variation versus pressure is very linear (figure 6). As the temperature and the salinity of the container were not constant to less than 0.002 during the experiment, $P$ values have had to be corrected to calculate the sensitivity $\partial P / \partial p$. The pressure corrections then take a simple form: $\delta P(p)=1.194 \times 10^{-4}-3.694 \times$ $10^{-9} p$, which leads a maximal residual error of $9 \times 10^{-7}$ in the index.

The sensor being compensated in temperature, pressure and wavelength, the PSD voltage expressed in position, can be calibrated in refractive index (see figure 7). Values measured during temperature compensation can be used for that purpose. Refractive index reference values are calculated with the Millard and Seaver algorithm [16]. For $p=0 \mathrm{dbar}$ and $S=$ 35 , the standard uncertainty of this algorithm is stated to be $4.7 \times 10^{-6}$ and its computation results in the following linear relation: $n=0.011496 \times P+1.335718\left(r^{2}=0.9992\right)$.

\section{Results of trials at sea}

Trials took place at sea in spring 2010, during an oceanographic campaign in the Bay of Biscay. A $2000 \mathrm{~m}$ depth profile has been realized in an area where density variations are mostly due to temperature variations. A first refraction index profile has been measured to the frequency of five samples per second and a down cast speed of $0.5 \mathrm{~m} \mathrm{~s}^{-1}$ (see figure 8). This profile has been expressed in salinity by inverting the Millard and Seaver algorithm. It is similar to the one obtained with a reference CTD profiler, Sea Bird Electronics, SBE $9^{+}$, used to recover the index sensor data, in that small salinity variation details can be compared. A second profile has been realized, at the same down cast speed, in a coastal area where density variations are mostly due to salinity variations. Once again, the index sensor is able to see the small salinity variations visible on the CTD profile, which proves the ability of this kind of sensor to be used at sea in regular applications. 


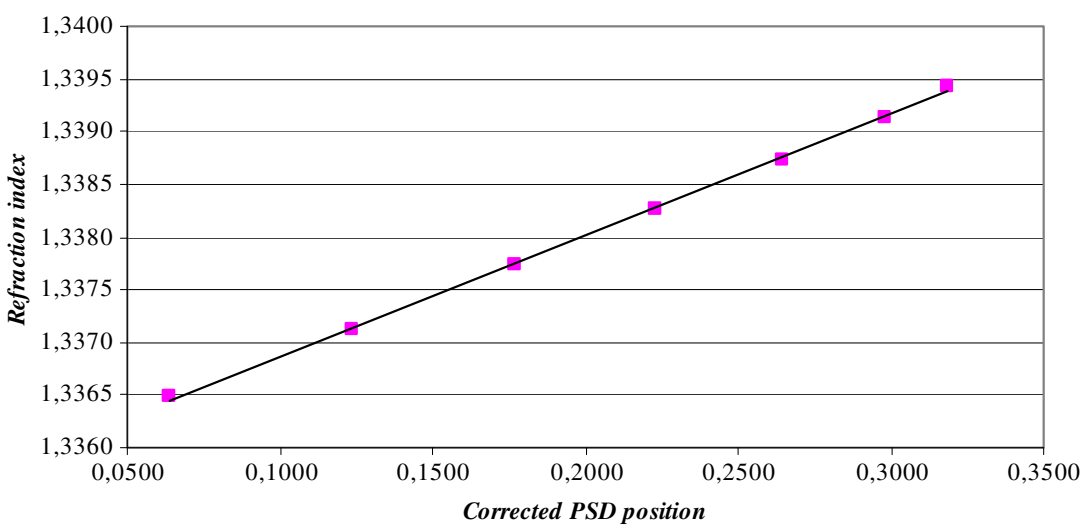

Figure 7. Result of the calibration of the corrected PSD positions as a function of the refractive index. The relation is found to be very linear (Pearson correlation sampling coefficient $r^{2}=0.9992$ ).
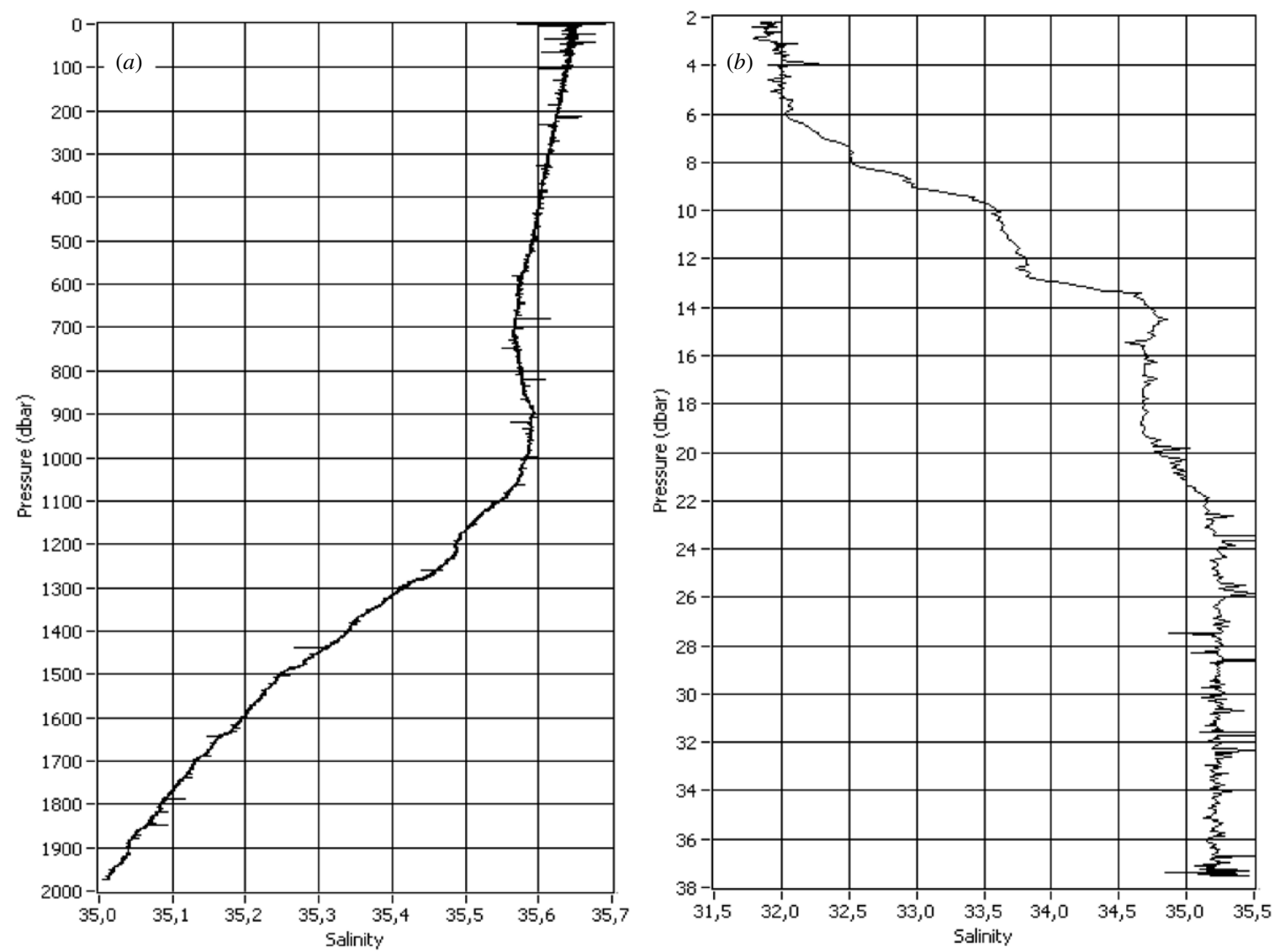

Figure 8. Examples of index profiles obtained during an oceanographic campaign in the Bay of Biscay. (a) A $2000 \mathrm{~m}$ depth profile that has been realized in an area where density variations are mostly due to temperature variations. Acquired at the frequency of five samples per second, it has been expressed in salinity by inverting the Millard and Seaver algorithm. (b) A profile obtained in a coastal area where density variations are mostly due to salinity variations. The two profiles are unfiltered and the response times of the index, temperature and pressure sensors have not been aligned, which can explain the visible spikes.

\section{Conclusion}

Conclusively, to assess absolute salinity and seawater density, the refractive index theoretical method exposed in 2009 by Malardé et al [9] has been used to develop an instrument called NOSS. In order to improve the compactness without losing the resolution capacities of the theoretical method, mirrors have been added to the prisms, and the beam path has been modified.
This design allowed the laser and the PSD to be held on the same level in the container.

This prototype has been tested in a calibration bath to obtain correction relations between the measured laser spot position and the temperature and wavelength variations. It has been also tested in a pressure tank to study the effect of pressure on the position. These measurements have shown that it was possible to correct this sensor in order to hold the required 
accuracy, on the refractive index, of $1 \mathrm{ppm}$ at atmospheric pressure and $3 \mathrm{ppm}$ under high pressure, which confirms the theoretical studies made previously.

First trials at sea have shown promising results but future studies are still necessary to improve the reliability and the thermal inertia of the sensor, and to find corrections to align the index measurement response time to the temperature sensor in order to improve salinity accuracy in strong temperature gradients. Measurements at higher pressures must also be foreseen in a new design.

\section{Acknowledgments}

Thanks to Z Y Wu for discussions, D Malardé for his contribution to prototype manufacturing and testing, the mechanical Research and Development team of Ifremer for technical assistance, F Colas for turbidity and fluorescence tests, C Schaeffer for the embedded software and A Bodolec for the hardware. This work was supported by the FUI under grant NOSS.

\section{References}

[1] IOC, SCOR and IAPSO 2010 The International thermodynamic equation of seawater 2010 (TEOS-2010): calculation and use of thermodynamic properties Intergovernmental Oceanographic Commission, Manuals and Guides No 56 UNESCO 196 pp

[2] Perkin R G and Lewis E L 1980 The practical salinity scale 1978: fitting the data IEEE J. Ocean. Eng. OE-5 9-16

[3] UNESCO 1983 Algorithm for computation of fundamental properties of seawater UNESCO Technical papers in Marine Sciences $36 \mathrm{pp}$

[4] McDougall T J, Jackett D R and Millero F J 2009 An algorithm for estimating absolute salinity in the global ocean Ocean. Sci. Discuss. 6 215-42

[5] Feistel R 2008 A Gibbs function for seawater thermodynamics for -6 to $80{ }^{\circ} \mathrm{C}$ and salinity up to $120 \mathrm{~g} / \mathrm{kg}$ Deep-Sea Res. I 55 1639-71

[6] Seitz S, Spitzer P and Brown R J C 2010 CCQM-P111 study on traceable determination of practical salinity and mass fraction of major seawater components Accredit. Qual. Assur. 15 9-17

[7] Seitz S, Feistel R, Wright D G, Weinreben S, Spitzer P and de Bièvre P 2010 Metrological traceability of oceanographic salinity measurement results Ocean. Sci. Discuss. 7 1303-46
[8] Mensah V, Le Menn M and Morel Y 2009 Thermal mass correction for the evaluation of salinity J. Atmos. Ocean. Technol. 26 665-72

[9] Malardé D, Wu Z Y, Grosso P, de Bougrenet de la Tocnaye J-L and Le Menn M 2009 High-resolution and compact refractometer for salinity measurements Meas. Sci. Technol. 20015204

[10] Saubade Ch 1984 Refringency laws and optical properties of water at various temperatures: I J. Phys. C: Solid State Phys. 17 3493-506

[11] Born E and Wolf H 1980 Principles of Optics: Electromagnetic Theory of Propagation, Interference and Diffraction of Light 6th edn (Cambridge: Cambridge University Press)

[12] Millero F J, Feistel R, Wright D G and McDougall T J 2008 The composition of standard seawater and the definition of reference-composition salinity Scale Deep-Sea Res. I 55 50-72

[13] Reisler E and Eisenberg H 1965 Refractive indices and piezo-optic coefficients of deuterium oxide, methanol and other pure liquids J. Chem. Phys. 43 3875-80

[14] Saubade C 1984 Refringency laws and optical properties of water at various temperatures: II. Macroscopic approach J. Phys. C: Solid State Phys. 17 3507-17

[15] Schiebener P, Straub J, Levelt Sengers J M H and Gallagher J S 1990 Refractive index of water and steam as function of wavelength, temperature and density J. Phys. Chem. Ref. Data $19677-717$

[16] Harvey A H, Gallagher J S and Levelt Sengers J M H 1998 Revised formulation for the refractive index of water and steam as a function of wavelength, temperature and density J. Phys. Chem. Ref. Data 27 761-74

[17] Millard R C and Seaver G 1990 An index of refraction algorithm for seawater over temperature, pressure, salinity, density and wavelength Deep-Sea Res. 37 1909-26

[18] Millero F J, Chen C T, Bradshaw A and Schleicher K 1980 A new high pressure equation of state for seawater Deep-Sea Res. 27A 255-64

[19] Safarov J, Millero F, Feistel R, Heintz A and Hassel E 2009 Thermodynamic properties of standard seawater: extension to high temperatures and pressures Ocean. Sci. 5 235-46

[20] SCOR/IAPSO 2007 Working Group 127 on Thermodynamics and Equation of state of Seawater, 'Refractive index of seawater', Meeting (Italy, 6-11 May 2007)

[21] Mahrt K-H and Waldmann C 1988 Field proven high speed micro optical density profiler sampling 1000 times per second with $10^{-6}$ precision Proc. OCEANS' 88 vol 2 pp 497-504

[22] Sellmeier W 1871 Zur Erklärung der abnormen Farbenfolge im spectrum einiger Substanzen Ann. Phys. Chem. 219 272-82

[23] Grosso P, Menn M L, de Bougrenet de la Tocnaye J-L, Wu Z Y and Malardé D 2010 Practical versus absolute salinity measurements, new advances in high performance seawater salinity sensors Deep-Sea Res. I 57 151-6 